Canadian

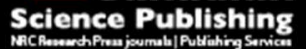

Canadian Journal of Civil Engineering Revue canadienne de génie civil

\title{
Volume change behaviour and microstructure of stabilized loess under cyclic freeze-thaw conditions
}

\begin{tabular}{|r|l|}
\hline Journal: & Canadian Journal of Civil Engineering \\
\hline Manuscript ID & cjce-2016-0052.R2 \\
\hline Manuscript Type: & Article \\
\hline Date Submitted by the Author: & 30 -Jun-2016 \\
\hline Complete List of Authors: & $\begin{array}{l}\text { Wang, Shenglin; University of Waterloo Faculty of Engineering, Civil and } \\
\text { Environmental Engineering; Lanzhou University, Key Laboratory of } \\
\text { Mechanics on Western Disaster and Environment Mechanics } \\
\text { Lv, Qingfeng; Lanzhou University, Key Laboratory of Mechanics on Western } \\
\text { Disaster and Environment Mechanics } \\
\text { Baaj, Hassan; University of Waterloo Faculty of Engineering, Civil and } \\
\text { Environmental Engineering } \\
\text { Li, Xiaoyuan; Lanzhou University, Key Laboratory of Mechanics on Western } \\
\text { Disaster and Environment Mechanics } \\
\text { Zhao, Yanxu; China Railway 21st Bureau Group Co., Ltd }\end{array}$ \\
\hline Keyword: & $\begin{array}{l}\text { stabilized loess; freeze-thaw cycle; frost heaving; thaw shrinkage; } \\
\text { microstructure; cement; lime; fly ash }\end{array}$ \\
\hline
\end{tabular}




\section{Volume change behaviour and microstructure of stabilized loess under cyclic freeze-thaw conditions}

Sheng-lin Wang, ${ }^{\mathrm{a}, \mathrm{b}}$, Qing-feng $\mathrm{Lv}^{\mathrm{b}}$, Hassan Baaj ${ }^{\mathrm{a}}$, Xiao-yuan $\mathrm{Li}^{\mathrm{b}}$, Yan-xu $\mathrm{Zhao}^{\mathrm{c}}$

a Department of Civil and Environmental Engineering, University of Waterloo, Waterloo, Ontario, Canada, N2L 3G1.

b Key Laboratory of Mechanics on Western Disaster and Environment Mechanics, Lanzhou University, Lanzhou, Gansu Province, China,730000.

c China Railway 21st Bureau Group Co., Ltd, Lanzhou, Gansu Province, China, 730000 .

E-mail addresses:s545wang@uwaterloo.ca (Sheng-lin Wang);

lvqf@1zu.edu.cn (Qing-feng Lv);

hassan.baaj@uwaterloo.ca (Hassan Baaj);

lixiaoyuan1988@yahoo.com (Xiao-yuan Li);

zhaoyx822@sina.com (Yan-xu Zhao).

Correspondent Author: Qing-feng Lv

E-mail address: lvqf@1zu.edu.cn

Address: 222 Tianshui South Road, School of Civil Engineering and Mechanics, Lanzhou University, Lanzhou, Gansu, China, 730000

Telephone Number: (86) 13909499095 
Abstract: Freeze-thaw action is considered to be one of the most destructive actions that can induce significant damage in stabilized subgrades in seasonally frozen loess areas. Laboratory tests include frost heave-thaw shrinkage and microstructure change during freeze-thaw cycles were conducted to evaluate the volume change rate of loess stabilized with cement, lime, and fly ash under the impact of cyclic freeze-thaw conditions. The loess specimens collapsed after eight freeze-thaw cycles (192h), but most stabilized loess specimens had no visible damage after all freeze-thaw cycles were completed. All of the stabilized loess samples underwent a much smaller volume change than the loess alone after the freeze-thaw cycles. Although surface porosity and equivalent diameter of stabilized loess samples increased, the stabilized loess can retain its microstructure during freeze-thaw cycles when the cement content was less than $6 \%$. To ensure freeze-thaw resistance of stabilized loess subgrades, the mix proportions of the three additives was recommended to be 4 to $5 \%$ cement, $6 \%$ lime, and $10 \%$ fly ash.

Keywords: stabilized loess; freeze-thaw cycle; frost heaving; thaw shrinkage; microstructure; cement; lime; fly ash. 


\section{Introduction}

Loess is a collapsible soil covering approximately 10\% of the Earth's surface, it appears at vast areas from Western Europe to China (Qian et al., 1985), across North America and in regions at South America. Loess consists essentially of silt-sized $(20-60 \mu \mathrm{m})$ primary quartz minerals that forms by high-energy earth-surface process (Jefferson et al., 2015). As a kind of Aeolian Quaternary deposit, natural loess has a characteristically loose structure, visible voids, a poorly-graded grain size distribution, and serious self-weight collapsibility (Gao, 1996; Zourmpakis et al., 2005).Chemical method, which means soil stabilization by hydraulic binders (Portland cement, lime and fly ash), has a high degree of soil development and a wide extent of utilization (Evstatiev, 1988; Zia and Fox, 2000).

The durability of subgrade soils induced by climatic changes in seasonally frozen are as namely, freeze-thaw and wet-dry cycles, have been recognised as a major factor in the poor engineering performance of such soils. Freeze-thaw action is considered to be one of the most destructive actions that can induce significant damage to a subgrade. The freezing of moisture present in the pore spaces of the soil structure results in formation of ice lenses and additional migration of water to the freezing front. During times of temperate weather, the ice thaws. This repeated freeze-thaw action degrades the integrity of the soil microstructure, indicating possible changes 
in particle aggregation and pore space distribution, and changes its engineering properties like bulk density, unconfined compressive strength, and hydraulic permeability (Rempel et al.,2007; Qi et al., 2008; Lv et al., 2014), even though the soil has been well compacted (Li et al., 2012)

Dempsey and Thompson (1973) evaluate different freeze-thaw cycle parameters for two typical Illinois soils stabilized with lime and cement, and advised on cooling rate, freezing temperature, length of freezing period, and thawing temperature. Viklander (1998) investigated the permeability and volume changes in compacted till due to freeze-thaw cycles, and found that vertical permeability slightly decreased with an increase in the number of freeze-thaw cycles. Parsons and Milburn (2003) evaluated the mass loss of soils stabilized with different additives by freeze-thaw testing. Arora and Aydilek (2005) conducted freeze-thaw tests on silty sand stabilized with $40 \%$ fly ash in combination with cement or lime, and found that the strength of specimens stabilized with fly ash and cement increased with an increasing number of freeze-thaw cycles, but lime-stabilized specimens suffered a decrease in strength. Zhang et al., (2002) were concerned with the physical-mechanical properties of lime-stabilized soil during freezing and found that the optimum lime content is about 12 to $15 \%$. Chen et al., (2010) investigated the effect of freeze-thaw cycles on soils stabilized with lime and a liquid stabilizer; it was found that the compressive strength of stabilized 
soils decreases with an increase in the number of freeze-thaw cycles. Wang et al., (2011) studied the stress-strain relationship and failure shapes of a cement- and lime-modified clay soil under different freeze-thaw cycles and found that their apparent cohesion decreased with an increase in the number of freeze-thaw cycles, but that there was no relationship between thermal regime and angle of internal shearing resistance. Lv et al., (2014) conducted freeze-thaw tests on loess stabilized with cement, lime, and fly ash in combination with cement or lime, and proposed an optimal ratio of the modifier based on the comprehensive strength, permeability, and freeze-thaw resistance performance under cyclic freeze-thaw regimes.

Many studies in the literature emphasized effects on freeze-thaw cycles on clay and silt; some also introduced additive application on soil stabilization. However, only limited studies have addressed the different deformation processes of compacted and chemical stabilized loess during freeze/thaw. Fine grained loess is frequently used as subgrade fill and slope material in northwest China. Due to poor particle size distribution, structure of loess is vulnerable to thermal and moisture change even it has been compacted in high density (Qi et al., 2008). Consequently, the primary objective of this study was to discuss volume change behaviour and soil morphology by carrying out frost heave and thaw shrinkage tests, with associated microstructural test and analysis. Based on the freeze-thaw resistance, 
optimal additive contents for loess stabilization could be suggested for engineering practice.

\section{Materials and test procedure}

\subsection{Materials}

(1) Loess

This paper takes a silty soil, the Lishi loess from Lanzhou, China. The undisturbed loess is light yellow, loose, uniform, and of low gravimetric moisture content, and it is a common construction material for subgrade and slope in North-west of China. Table 1 details the physical properties of the loess. The grain size distribution curve of Lanzhou loess is shown in Figure 1.

$<$ INSERT TABLE 1 HERE $>$

$<$ INSERT FIGURE 1 HERE $>$

(2) Additives

Additives used in these experiments were Portland cement, lime and fly ash:

Cement used in this test was ordinary Portland cement (type I) which had a compressive strength of $42.5 \mathrm{MPa}$ after 28 days' curing.

Lime in this test consists more than $90 \%$ (by weight) of activity calcium oxide $(\mathrm{CaO})$, with less than $2 \%$ (by weight) of ignition loss. 
Fly ash was obtained from a thermal powerplant in Lanzhou. It is a fine, powdery material and is composed primarily of spherical glassy particles. This fly ash has a calcium oxide content of $7.14 \%$, thus is characterized as Class F. Table 2 shows the chemical component of fly ash in this research. $<$ INSERT TABLE 2 HERE $>$

\subsection{Sample preparation}

Sample preparation consisted of six steps: drying, sieving, mixing, compaction, curing, and extrusion.

Before samples mixing, all loess and additives were stored in an oven-dried at a temperature of $105^{\circ} \mathrm{C}$ for $12 \mathrm{~h}$. Afterwards, they should pass a $2 \mathrm{~mm}$ (No. 10) sieve. Values of added mass of water were calculated according to the optimum moisture content of this loess $(16.9 \%)$ and the total dry mass of each sample.

Dry loess, lime, and fly ash powder were initially homogenised in a mixer as water was sprinkled thereon. Then they were allowed to equilibrate for $12 \mathrm{~h}$ before mixing the cement in. After mixing, the soil was compacted into a metallic mould (inner diameter, $72.5 \mathrm{~mm}$ ) using a sample compaction machine at a speed of $2 \mathrm{~mm} / \mathrm{s}$ (Fig. 2). These samples were then sealed and cured in a humidity and temperature-controlled $\left(20^{\circ} \mathrm{C}\right)$ curing chamber for 28 days. During the sample curing process, it was found that the moisture 
content of samples have a big possibility to be changed under $100 \%$ humidity curing even they have been well sealed. By lowering the humidity to $80 \%$, the risk of moisture absorption of samples from external environment has been minimized.

According to previous research, in this study fly ash content was fixed at $10 \%$ and lime and cement contents varied. Based on previous findings, various cement $(4 \%$ and $5 \%)$ and lime $(3 \%, 6 \%$ and $9 \%)$ contents were added to these loess samples. All test samples were made at the same moisture content $(16.9 \%)$ and density $\left(1.64 \mathrm{~g} / \mathrm{cm}^{3}\right)$. Samples were made in two groups: Groups A and B, Group B was used for microstructural testing while Group A was prepared for frost heave testing and microstructural testing after cyclic freezing and thawing. The parameters of each modified loess sample are presented in Table 3.

$<$ INSERT TABLE 3 HERE $>$

\subsection{Freeze-thaw cycles}

Ding et al. (2007) indicated that the physical properties of loess and modified loess would be stable after 8 to 10 freeze-thaw cycles. Hence the samples were supposed to experience 10 freeze-thaw cycles after 28 days' curing. Each cycle includes freezing for $12 \mathrm{~h}$ at $-15^{\circ} \mathrm{C}$ and thawing for 12 hours at $5{ }^{\circ} \mathrm{C}$ and $100 \%$ relative humidity. Each cycle comprised $12 \mathrm{~h}$ of freezing and $12 \mathrm{~h}$ of thawing. Samples were designed to have been exposed 
to an open system which had sufficient moisture supply. Free potable water was available to the porous plates under the specimens to permit the specimens to absorb water through capillary action during thawing.

Apparatus designed for this test is shown in Figure 3. Soil samples were placed in a modified freezer; two heating rods were inserted into the freezer to heat the surrounding atmosphere. Firstly, the freezer was turned on and the temperature allowed to stabilize at $-15^{\circ} \mathrm{C}$ for $12 \mathrm{~h}$; thereafter, the freezer was turned off and the heating rod used to increase the temperature to $5^{\circ} \mathrm{C}$ for another $12 \mathrm{~h}$ before turning off the heating rod and continuing with the next freeze-thaw cycle. Additionally, the whole process had a continuous moisture supply available in the bottom of the chamber.

$<$ INSERT FIGURE 3 HERE $>$

\subsection{Freeze heave and thaw shrinkage tests}

Before placing the samples into the freezing cells, three indicator nails were inserted in two axial directions: this procedure should be done carefully in order not to damage the samples. After each freeze-thaw cycle, changes in the radius and height of each sample were recorded using gradated plates next to the nails so that the volume change of each sample could be calculated. Each test was repeated 3 times and average value of sample volume was determined for each sample. If the standard deviation (SD) between figures exceeds $5 \%$, then singular data will be removed therefore 
sample volume will be calculated by the average of the rest two. However, if the standard deviation is still larger than $5 \%$, the test should be done again.

\subsection{Microstructure test}

A scanning electron microscope (SEM) was used in the evaluation of each sample's microstructure test (model SU-1500,HITACHI, Japan). By way of test preparation, samples were cut into flat slices with a diameter of 5mm: they were then blow-dried. Next, the slices were gold-plated by sputter coating to render them conductive before SEM examination. Once an SEM micrograph of each sample was obtained, images were de-noised by means of the "Wavemenu" toolbox in MATLAB" (using wavelets of Sym 4, and Level 2). After the segmentation of each image, particles and pores were counted and measured using Image Pro Plus software.

\section{Results and discussion}

\subsection{Frost heave and thaw shrinkage}

The specimens were designed to have been exposed to sufficient moisture supply during freeze-thaw cycles so that moisture migration could be continuous. Figure 4 shows the failure of loess, and some stabilized loess, samples after eight to 12 freeze-thaw cycles.

\section{$<$ INSERT FIGURE 4 HERE $>$}

Pores in loess are generally divided into four types based on their diameters, i.e., super pore $(>250 \mu \mathrm{m})$, large pore $(250-16 \mu \mathrm{m})$, median pore 
$(16-4 \mu \mathrm{m})$, small pore $(4-1 \mu \mathrm{m})$, and micro pore $(<1 \mu \mathrm{m})$. Super and large pores which can be observed by naked eye are the main reason lead to high permeability and self-weight collapsibility in natural loess. Compacted loess; on the other hand, has a relatively minimized number of super and large pores but a greater number of small and micro pores. Pore size distribution of natural and compacted loess was listed in Table 4 based on lab study. $<$ INSERT TABLE 4 HERE $>$

When temperature drops below $0{ }^{\circ} \mathrm{C}$, pore water does not freeze immediately; instead, gravity water in soil starts to turn into solid ice at lower temperature $T_{\mathrm{SC}}$ and releases heat (Figure 5, re-drawn after Andersland (2003)). $T_{\mathrm{SC}}$ for fine grain soil like loess will be as low as $-5^{\circ} \mathrm{C}$ (Qi et al., 2010). In the process of gravity water freezing, the temperature in soil reaches a dynamic equilibrium at $T_{\mathrm{F}}$, continued by the double-layer water freezing process during which the temperature will decrease dramatically because the amount of such water and its reaction heat are both insignificant. $<$ INSERT FIGURE 5 HERE $>$

The freezing process of pore water displaced soil particles and separated soil aggregates, consequently the interlocking of soil grains was broken and the soil structure changed. Thus soil cohesion and mechanical strength decreased (Qi et al., 2008). As the temperature increased, the ice melted, and pore and specimen volume decreased, but the destruction of the 
interlocking will be irrecoverable (Wang et al., 2006).

As shown in Figure 4(a), cracks appeared on the loess specimens after seven freeze-thaw cycles (168h), and they totally collapsed by the expansion and shrinkage stresses after another freeze-thaw cycle (192 h). Most stabilized loess specimens had no visible damage after all freeze-thaw cycles. However, as shown in Figures 4 (c) to (e), B69 (6\% cement-, 9\% lime -, and $10 \%$ fly ash-stabilized loess specimens) showed obvious cracks after seven freeze-thaw cycles (168h), and they were entirely damaged after nine freeze-thaw cycles (216h). Tiny cracks also appeared on B66 (6\% cement-, 6\% lime -, and $10 \%$ fly ash-stabilized loess specimens), but after eight freeze-thaw cycles (192h) (Figure 4(f)).

During freezing, the most important effect is moisture migration toward the ice segregation front due to the open nature of the system; this effect became more distinct in the silt-like loess under constant moisture supply (Qi et al.,2008).

To detect volume change accurately, we defined $\eta$ as the rate of volume change of samples throughout the freeze-thaw cycles:

$$
\eta=\frac{V_{1}-V_{0}}{V_{0}} \times 100 \%
$$

Where $V_{0}=$ initial volume $\left(\mathrm{cm}^{3}\right)$; and $V_{1}=$ volume at a certain time later $\left(\mathrm{cm}^{3}\right)$.

Figures 6 to 12 show average volume change rate $\eta$ for loess and stabilized loess samples during the imposed freeze-thaw cycles. 
The loess underwent significant swelling after initial freezing, but when melting, it shrunk significantly. The range between freezing and shrinking increased with an increase in the number of freeze-thaw cycles. Because of the residual soil cohesion, the shrinkage was smaller than the swelling increment caused by pore water freezing, and the material reached a dynamic equilibrium after approximately $60 \mathrm{~h}$ matching previous work (Majdi et al.,1993; Eigenbrod, 1996).

As shown in Figures 6 to 12, all of the stabilized loess samples underwent a much smaller volume change than the loess alone (by approximately 20\%). Their volumetric change upon freezing and thawing was less than $0.5 \%$. Moreover, increased cement or lime contents could both enhance resistance against frost heave, but the impact of these content changes was not remarkable. Samples A66 and A69 had already collapsed after multiple freeze-thaw cycles: from Figure 9, it can be seen that A63 and A69 had higher rates of volume change after 168h. This phenomenon resulted from the over-rigid of the samples due to the high additive proportion. During the last two cycles, these samples had brittle damage, so the samples had larger plastic/residue deformations, which means at the thawing process, they could not shrink to former volumes. Meanwhile, the volume change between each cycle had also been reduced. Therefore, the cement content should be less than $6 \%$ for best resistance to frost heave and 
thaw shrinkage. To ensure freeze-thaw resistance of stabilized loess subgrades, a reasonable proportion of the three additives should be 4 to $5 \%$ cement, $6 \%$ lime, and 10\% fly ash, where the stabilized loess samples were proved to have lower volume vibration.

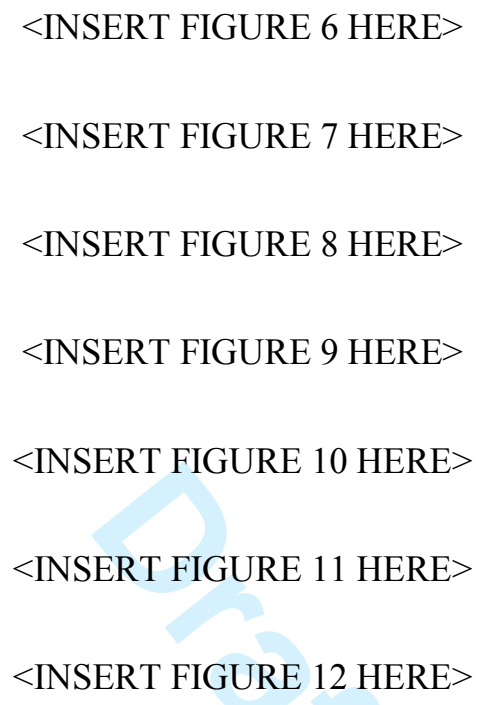

\subsection{Microstructure of loess and stabilized loess}

The SEM could reveal the pore properties and forms of inter-particle contact in both loess and stabilized loess samples. Micrographs of loess and some stabilized loess samples, before and after freeze-thaw cycling, are shown in Figure 13.

As shown in Figure 13(a), there were few open voids in the loess samples. Fine loess particles, mostly in the form of quart silt grains, were attached to the surfaces of larger grains; the edges of such grains were sharp. Meanwhile, most of the loess particles made contact in face-to-face form so that the compacted loess had a generally tight structure (Delage et al.,2005). 
However, after freeze-thaw cycling, macro-pores appeared and some particles made contact in point-to-point form due to the cryogenic pressure of growing ice crystals (Figure 13(b)). According to general appearance of the soil images, freeze-thaw cycles resulted in an increased porosity, a looser structure in loess, and consequently: volumetric expansion. Furthermore, this process was irreversible, so the microstructure could not be recovered during thawing: therefore, after multiple freeze-thaw cycles, the loess collapsed.

As shown in Figures 13 (c, e, g, and i), the influence of cement, lime, and fly ash were significant: acicular hydration products of cement and hydration gels of lime and fly ash, including calcium silicate hydrates $(\mathrm{C}-\mathrm{S}-\mathrm{H})$ and calcium aluminate hydrates $(\mathrm{C}-\mathrm{A}-\mathrm{H})$ could be seen in SEM micrographs. Acicular C-S-H particles (Angelova et al., 2007), in stabilized loess, acted as a bridge between particles: they became thicker and more densely concentrated as the cement content increased. More hydraulic products can be observed with the growth of the additive percentage. Additionally, the effects of lime and fly ash were characteristic of complicated physial-chemical processes, such as cation exchange, flocculation-agglomeration, pozzolanic reaction, and carbonation. The hydration gel filled the small inter-grain pores so that fewer pores were seen in the tighter, stabilized, loess microstructures.

Figures $13(\mathrm{~d}, \mathrm{f}, \mathrm{h}$, and $\mathrm{j}$ ) manifest that multiple freeze-thaw cycles also 
exerted conspicuous influence on modified loess samples: fine particles were easily detached from bigger aggregates during sample preparation, and some large grains became isolated without insufficient constraint and several deep inter-granular pores appeared. Nonetheless, repeated freeze-thaw cycles did not change either the way particles made contact or the main microstructure of stabilized loess samples. Moreover, hydration products of the additives still remained so that most small particles gathered in the form of large grain aggregates as before. With increasing cement and lime contents, the negative influence exerted by repeated freeze-thaw cycling proved minimal. Overall, these additives could improve the loess microstructure under certain conditions (cement content 4 to $5 \%$, lime content 6 to $9 \%$, and fly ash content $10 \%$ by mass of loess respectively).

$<$ INSERT FIGURE 13 HERE $>$

\subsection{Quantitative analysis of SEM micrographs}

Quantitative analysis of the micrographs can describe pore sizes and their shapes in the specimen cross-sections. Image process for SEM includes several steps: filtering (de-noising), image segmentation, particle edges detection and soil voids analysis.

The simplest way to segment image is converting the grayscale image into a binary image with threshold. The output image replaces all pixels in the input image with luminance greater than threshold (between $0 \sim 1$ ) with 
the value 1 (white) and replaces all other pixels with the value 0 (black). In this test, Otsu's algorithm was used to determine the optimal threshold. The Otsu's algorithm assumes that the image contains two classes of pixels following bi-modal histogram (foreground pixels and background pixels), it then calculates the optimum threshold separating the two classes so that their combined spread (intra-class variance) is minimal, so that their inter-class variance is maximal (Otsu, 1975). The Otsu's algorithm for threshold acquirement is achieved by function of graythresh in MATLAB. Figure 14 shows image segmentation and soil voids detecting using Otsu's algorithm (sample: \#39). After segmentation, white area represents soil particles and black area represents soil voids.

\section{$<$ INSERT FIGURE 14 HERE $>$}

Surface porosity $n$ was then introduced to represent the ratio of the area of voids to the total area and is generally expressed as a percentage:

$$
n=\frac{m_{v}}{m} \times 100 \%
$$

Where $m_{v}=$ area of the voids $\left(\mu m^{2}\right) ; m=$ total cross-sectional area of the specimen $\left(\mu m^{2}\right)$.

The equivalent diameter $d$ of each void can also be calculated according to the formula below (Moore et al., 1995):

$$
\log (P)=\frac{d}{2} \times \log (A)+C
$$

Where $P=$ equivalent perimeter of each void $(\mu m) ; A=$ area of each void 
$\left(\mu m^{2}\right)$, and $C$ is a constant determined by the fractal dimension of the voids.

For each sample, analysis was conducted on 5 different SEM images, and average values of $n$ and $d$ were determined for each sample. Again, if the standard deviation (SD) between figures exceeds $5 \%$, then singular data will be removed; but, if the standard deviation of the rest is still larger than $5 \%$, the test should be done again. The average value of surface porosity $n$ and average equivalent diameter $d$ of each modified loess sample at all cement and lime contents are summarised in Figures 15 and 16, respectively, with standard deviation of $5 \%$.

$<$ INSERT FIGURE 15 HERE $>$

$<$ INSERT FIGURE 16 HERE $>$

The surface porosity of this loess was approximately $17 \%$ before freeze-thaw cycling, and 22\% thereafter. Figure 15 indicated that the surface porosity of loess was much higher than any stabilized loess. The surface porosity of stabilized loess decreased when either the cement or lime content increased. A similar trend was seen in the data after multiple freeze-thaw cycles; however, all cross-sections contained a greater percentage of void area (up to twice that before cycling at the same ratio), with the biggest void area increased by approximately $13 \%$.

Mercury intrusion porosimetry (MIP) test results for samples before freeze-thaw cycles were presented as well in Figure 15, as seen from the 
figure, the result of the MIP test shows similar trend with the image processing method. But the area of voids calculated by MIP is generally lower. Two main reasons lead to this phenomenon: First, MIP has limitations when applied to materials that have irregular pore geometry or voids are sealed among soil particles. Therefore, some voids can not be calculated by MIP test. Second. In order to observe the true morphology of soil particles, the SEM sample were not polished. Therefore, during image segmentation some void areas have been enlarged (see Fig. 14).

Trends of average equivalent diameter $d$ appeared to behave similarly to those of surface porosity: stabilized loess had larger voids after multiple freeze-thaw cycles whereas the greatest difference was that the ascending trend will be well controlled by sufficient additive addition, especially in contrast to the loess alone $(10.6 \mu \mathrm{m}$ before multiple freeze-thaw cycles and $13.6 \mu \mathrm{m}$ thereafter). Larger voids will allow more gravity water and double-layer water existing. With repeated freezing and thawing, these voids become even bigger and more connected, providing convenience for moisture and salt migration. Nevertheless, being subjected to cyclic freezing and thawing, not only did the surface porosity increased, but the equivalent diameter also increased at high additive rates (i.e. at cement contents greater than $6 \%$ and lime contents greater than $3 \%$ ). At this point, too much cement and lime will result in an over-stiffening of the samples, thus the soil mass 
will be more vulnerable to effects of subsequent re-freezing.

\section{Conclusions and discussion}

From the laboratory tests and analyses of the data, following conclusions and discussions can be drawn:

(1) Samples tested in this study showed that the loess specimens were destroyed after eight freeze-thaw cycles (192h). Most stabilized loess specimens suffered no visible damage after all freeze-thaw cycles, but $6 \%$ cement-, 9\% lime-, and 10\% fly ash-stabilized loess specimens showed obvious cracking after seven freeze-thaw cycles (168h), and were also destroyed after 9 freeze-thaw cycles (216h).

(2) All of stabilized loess samples underwent a much smaller (by approximately $20 \%$ ) volume change than the loess alone after freeze-thaw cycling. A63 and A69 had higher rates of heave and reduced volume change between each cycle.

(3) Additives changed the forms of inter-particle contact in loess: hydration products were also generated which not only bound the loess particles in the form of large aggregates, but also filled the small inter-grain pores. Although the surface porosity and equivalent diameter of stabilized loess increased, the stabilized loess retained its microstructure during freeze-thaw cycling when the cement content was less than $6 \%$.

(4) To ensure freeze-thaw resistance of stabilized loess subgrades, the 
proportions of the three additives should be 4 to $5 \%$ cement, $6 \%$ lime, and $10 \%$ fly ash: thereat, the stabilized loess samples had both a low volume change and suffered few adverse effects.

(5) During the subgrade construction in field, the moisture content of the soil should be low enough (only satisfy the compaction requirement) so that additives could absorb as much ground water as possible during raining and snowing. The more water exists in soil, the more severe frost heave phenomenon will take place.

\section{Acknowledgement}

The work was supported by National Natural Science Foundation of China (Project No. 51469001) and by Project of The Science and Technology Foundation of China Railway Construction Co., Ltd. (No. 12-C32).

\section{References}

Akagawa, S., and Fukuda, M. 1991. Frost heave mechanism in welded tuff. Permafrost and Periglacial Processes, 2(4), 301-309. doi:10.10 02/ppp.3430020405.

Andersland, O. B. and Ladanyi, B. 2003. Frozen ground engineering (Second edition). John Wiley \& Sons, Inc., New York. 
Angelova, R. N. 2007. Loess-cement long-term strength-a facilitating factor for loess improvement applications. Geologic Balcanica, 36, 21-24.

Arora, S., and Ahmet H. A. 2005. Class F fly-ash-amended soils as highway base materials. Journal of Materials in Civil Engineering, 17(6): 640-649.

Chen, Y., and Tan, Y. Q. 2012. Test study on road performance of soils stabilized by liquid stabilizer in seasonally frozen regions. In Advanced Engineering Forum. Trans Tech Publications, Switzerland, Vol. 5, pp. 310-315.

Delage P, Cui Y J, and Antoine P. 2005. Geotechnical problems related with loess deposits in Northern France, In Proceedings of the International Conference on Problematic Soils, Famagusta, North Cyprus, 25-27 May 2005. Eastern Mediterranean University Press, Famagusta, Vol. 2, pp. $517-540$.

Dempsey, B. J., and Thompson, M. R. 1973. Vacuum saturation method for predicting freeze-thaw durability of stabilized materials. In 52nd Annual Meeting of the Highway Research Board, Washington, D. C., 22-26 January 1973. Transportation Research Board, New York, Vol. 442, pp. 44-57.

Ding, M. J., Wang, L. J., and Feng, Z. 2007. Test study on improved soils as fills of subgrade of high-speed railway. Journal of Beijing Jiaotong 
University, 31(4), 65-67. (in Chinese).

Eigenbrod, K. D. 1996. Effects of cyclic freezing and thawing on volume changes and permeabilities of soft fine-grained soils. Canadian Geotechnical Journal, 33(4), 529-537. doi: 10.1139/t96-079-301.

Evstatiev, D. 1988. Loess improvement methods. Engineering Geology, 25 (2-4), 341-336. doi:10.1016/0013-7952(88)90036-1.

Gao, G. R. 1996. The distribution and geotechnical properties of loess soils, lateritic soils and clayey soils in China. Engineering Geology, 42(1), 95-104. doi:10.1016/0013-7952(95)00056-9.

Jefferson, I., Rogers, C., Evststiev, D., and Karastanev, D. 2015. Improvement of collapsible loess in Eastern Europe. In Ground Improvement Case Histories: Compaction, Grouting and Geosynthetics. Edit by B. Indraratna, J. Chu and C. Rujikiatkamjorn. Butterworth-Heinemann. pp. 215-262.

Li, G., Ma, W., Zhao, S., Mao, Y., and Mu, Y. 2012. Effect of freeze-thaw cycles on mechanical behavior of compacted fine-grained soil. In Cold Regions Engineering 2012: Sustainable Infrastructure Development in a Changing Cold Environment, Quebec City, Quebec, August 19-22 2012. American Society of Civil Engineers, New York, pp. 72-81. doi: 10.1061/9780784412473.008.

Lv, Q. F., Li, X. Y., Zhao Y. X., and Wang S. X. 2014. The properties of the 
modified loess under the freeze-thaw cycles. Journal of Central South University (Science and Technology), 45(3), 819-825. (in Chinese).

Othman, M. A., and Benson, C. H. 1993. Effect of freeze-thaw on the hydraulic conductivity and morphology of compacted clay. Canadian Geotechnical Journal, 30(2), 236-246. doi: 10.1139/t93-020.

Moore, C. A, and Donaldson, C, F. 1995. Quantifying soil microstructure using fractals. Geotechnique, 45(1), 105-116. doi: 10.1680/geot.1995.45.1.105.

Otsu, N. 1975. A threshold selection method from gray-level histograms. Automatica, 11(285-296): 23-27.

Parsons, R. L., and Milburn, J. P. 2003. Engineering Behavior of Stabilized Soils. Transportation Research Record: Journal of the Transportation Research Board, Vol. 1837, 20-29.

Qi, J. L., Ma, W., and Song, C. X. 2008. Influence of freeze-thaw on engineering properties of a silty soil. Cold Regions Science and Technology, 53(3), 397-404. doi:10.1016/j.coldregions.2007.05.010.

Qi, J. L, and Ma, W. 2010. State-of-art of research on mechanical properties of frozen soils. Rock and Soil Mechanics, 31(1), 133-143. (in Chinese).

Qian, H. J., Luo, Y. S., and Wang, J. T. 1985. Collapsed loess foundation. China Architecture and Building Press, Beijing. (in Chinese).

Rempel, A. W. 2007. Formation of ice lenses and frost heave. Journal 
of Geophysical Research: Earth Surface, 112(F2). doi:10.1029/2006J F000525.

Rogers, C. D. F. 1995. Types and distribution of collapsible soils. In Genesis and properties of collapsible soils. Edited by E. Derbyshire, T. Dijkstra and I. J. Smalley. Springer Netherlands. pp. 1-17.

Viklander, P. 1998. Permeability and volume changes in till due to cyclic freeze/thaw. Canadian Geotechnical Journal, 35(3), 471-477. doi: $10.1139 / \mathrm{t} 98-015$.

Wang, D. Y., Ma, W., Niu Y. H, Chang, X. X, and Wen, Z. 2007. Effects of cyclic freezing and thawing on mechanical properties of Qinghai-Tibet clay, Cold Regions Science and Technology, 48(1), 34-43. doi:10.1016/j.coldregions.2006.09.008.

Wang, T. L., Liu, J. K, and Tian, Y. H. 2011. Static properties of cement-and lime-modified soil subjected to freeze-thaw cycles. Rock and Soil Mechanics, 32(1), 193-198. (in Chinese).

White, T. L., and P. J. Williams. 1999. The influence of soil microstr ucture on hydraulic properties of hydrocarbon-contaminated freezing ground. Polar Record, 35(192): 25-32. doi: http://dx.doi.org/10.1017 /S0032247400026309.

Zhang L. X, and Wang J.C. 2002. Experimental study on frost heaving behaviors of lime soil. Chinese Journal of Geotechnical Engineering, 
24(3), 336-339. (in Chinese).

Zia, N., and Fox, P. 2000. Engineering properties of loess-fly ash mixt ures for roadbase construction. Transportation Research Record: Jour nal of the Transportation Research Board, (1714), 49-56. doi: http:// dx.doi.org/10.3141/1714-07.

Zourmpakis, A. 2005. Factors affecting bonding in loess soils. Ph.D. Thesis. University of Birmingham, Birmingham, UK. 
Table 1 The physical properties of loess

\begin{tabular}{ll}
\hline Parameters & Test results \\
\hline Specific gravity of soil solids $/ G_{s}$ & 2.59 \\
Liquid limit $/ \%$ & 24.4 \\
Plastic limit $/ \%$ & 16.2 \\
Optimum moisture content $/ \%$ & 16.9 \\
Maximum dry density $/\left(\mathrm{g} / \mathrm{cm}^{3}\right)$ & 1.64 \\
\hline
\end{tabular}

Table 2 Chemical component of fly ash

\begin{tabular}{cccccc}
\hline $\begin{array}{c}\text { Chemical } \\
\text { Component }\end{array}$ & $\mathrm{SiO}_{2}$ & $\mathrm{CaO}$ & $\mathrm{MgO}$ & $\mathrm{Al}_{2} \mathrm{O}_{3}$ & $\mathrm{Fe}_{2} \mathrm{O}_{3}$ \\
\hline $\begin{array}{c}\text { Rate of weight } \\
(\%)\end{array}$ & 47.88 & 7.14 & 2.57 & 25.10 & 10.13 \\
\hline $\begin{array}{c}\text { Chemical } \\
\text { Component }\end{array}$ & $\mathrm{Na}_{2} \mathrm{O}$ & $\mathrm{FeO}$ & $\mathrm{MnO}$ & $\mathrm{K}_{2} \mathrm{O}$ & $\begin{array}{c}\text { Ignition Loss } \\
\left(950^{\circ} \mathrm{C}\right)\end{array}$ \\
\hline $\begin{array}{c}\text { Rate of weight } \\
(\%)\end{array}$ & 2.59 & 0.70 & 0.32 & 0.98 & 2.59 \\
\hline
\end{tabular}


Table 3 Parameters of loess and modified loess samples

\begin{tabular}{|c|c|c|c|c|c|c|c|c|c|c|}
\hline \multirow[b]{2}{*}{ No. } & \multirow{2}{*}{$\begin{array}{c}\text { Loess } \\
\text { Mass } \\
(\mathrm{g})\end{array}$} & \multicolumn{2}{|c|}{ Cement } & \multicolumn{2}{|c|}{ Lime } & \multicolumn{2}{|c|}{ Fly ash } & \multicolumn{2}{|c|}{ Water } & \multirow{2}{*}{$\begin{array}{r}\text { Sample } \\
\text { height } \\
\text { (cm) }\end{array}$} \\
\hline & & $\begin{array}{l}\text { Rate } \\
(\%)\end{array}$ & $\begin{array}{c}\text { Mass } \\
\text { (g) }\end{array}$ & $\begin{array}{l}\text { Rate } \\
(\%)\end{array}$ & $\begin{array}{c}\text { Mass } \\
\text { (g) }\end{array}$ & $\begin{array}{l}\text { Rate } \\
(\%)\end{array}$ & $\begin{array}{c}\text { Mass } \\
(\mathrm{g})\end{array}$ & $\begin{array}{c}\text { Moisture } \\
\text { content } \\
(\%)\end{array}$ & $\begin{array}{c}\text { Mass } \\
(\mathrm{g})\end{array}$ & \\
\hline 00 & 400 & $0 \%$ & 0 & $0 \%$ & 0 & $0 \%$ & 0 & $16.9 \%$ & 68 & 7.0 \\
\hline 33 & 400 & $3 \%$ & 12 & $3 \%$ & 12 & $10 \%$ & 40 & $16.9 \%$ & 79 & 8.0 \\
\hline 36 & 400 & $3 \%$ & 12 & $6 \%$ & 24 & $10 \%$ & 40 & $16.9 \%$ & 81 & 8.2 \\
\hline 39 & 400 & $3 \%$ & 12 & $9 \%$ & 36 & $10 \%$ & 40 & $16.9 \%$ & 83 & 8.4 \\
\hline 43 & 400 & $4 \%$ & 16 & $3 \%$ & 12 & $10 \%$ & 40 & $16.9 \%$ & 80 & 8.1 \\
\hline 46 & 400 & $4 \%$ & 16 & $6 \%$ & 24 & $10 \%$ & 40 & $16.9 \%$ & 82 & 8.3 \\
\hline 49 & 400 & $4 \%$ & 16 & $9 \%$ & 36 & $10 \%$ & 40 & $16.9 \%$ & 84 & 8.5 \\
\hline 53 & 400 & $5 \%$ & 20 & $3 \%$ & 12 & $10 \%$ & 40 & $16.9 \%$ & 81 & 8.2 \\
\hline 56 & 400 & $5 \%$ & 20 & $6 \%$ & 24 & $10 \%$ & 40 & $16.9 \%$ & 83 & 8.4 \\
\hline 59 & 400 & $5 \%$ & 20 & $9 \%$ & 36 & $10 \%$ & 40 & $16.9 \%$ & 85 & 8.6 \\
\hline 63 & 400 & $6 \%$ & 24 & $3 \%$ & 12 & $10 \%$ & 40 & $16.9 \%$ & 81 & 8.2 \\
\hline 66 & 400 & $6 \%$ & 24 & $6 \%$ & 24 & $10 \%$ & 40 & $16.9 \%$ & 83 & 8.4 \\
\hline 69 & 400 & $6 \%$ & 24 & $9 \%$ & 36 & $10 \%$ & 40 & $17 \%$ & 85 & 8.6 \\
\hline
\end{tabular}

Table 4 Pore size distribution of natural and compacted loess

\begin{tabular}{cccccc}
\hline & \multicolumn{5}{c}{ Percentage of pores based on diameter (\%) } \\
\cline { 2 - 6 } Degree of \\
\cline { 2 - 6 } Compaction & Super-size & Large-size & Median-size & Small-size & Micro-size \\
& $(>250 \mu \mathrm{m})$ & $(250-16 \mu \mathrm{m})$ & $(16-4 \mu \mathrm{m})$ & $(4-1 \mu \mathrm{m})$ & $(<1 \mu \mathrm{m})$ \\
\hline \multirow{2}{*}{$\begin{array}{c}\text { Natural Loess } \\
\text { Compacted over } \\
90 \%\end{array}$} & 0.8 & 7.5 & 64.3 & 25.5 & 1.9 \\
\hline
\end{tabular}




\section{Table Titles (Captions)}

Figure 1 Grain size distribution of Lanzhou loess

Figure 2 Metallic mould and sample compaction

Figure 3 Apparatus for frost heaving and thaw settlement test

Figure 4 Loess and stabilized loess after the freeze-thaw cycles

Figure 5 Freezing process of soil

Figure 6 Volume change rate of loess and modified loess during the freeze-thaw cycles when cement content was $3 \%$

Figure 7 Volume change rate of loess and modified loess during the freeze-thaw cycles when cement content was $4 \%$

Figure 8 Volume change rate of loess and modified loess during the freeze-thaw cycles when cement content was $5 \%$

Figure 9 Volume change rate of loess and modified loess during the freeze-thaw cycles when cement content was $6 \%$

Figure 10 Volume change rate of loess and modified loess during the freeze-thaw cycles when lime content was $3 \%$

Figure 11 Volume change rate of loess and modified loess during the freeze-thaw cycles when lime content was $6 \%$

Figure 12 Volume change rate of loess and modified loess during the freeze-thaw cycles when lime content was $9 \%$

Figure 13 SEM images of loess and modified loess specimens before and after the freeze-thaw cycles $(\times 500)$

Figure 14 De-noised image and image segmentation (sample: \#39)

Figure 15 Surface porosity of stabilized loess before and after the freeze-thaw cycles

Figure 16 Average equivalent diameter of modified loess samples before and after the freeze-thaw cycles 


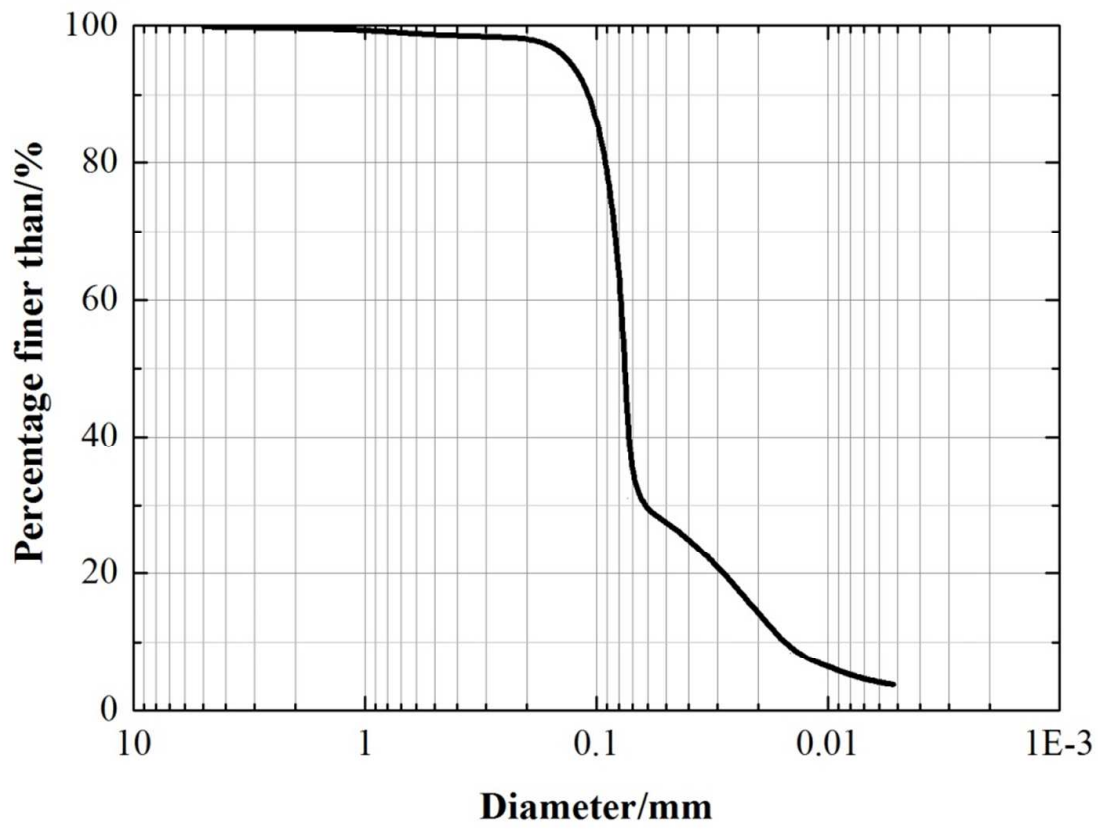




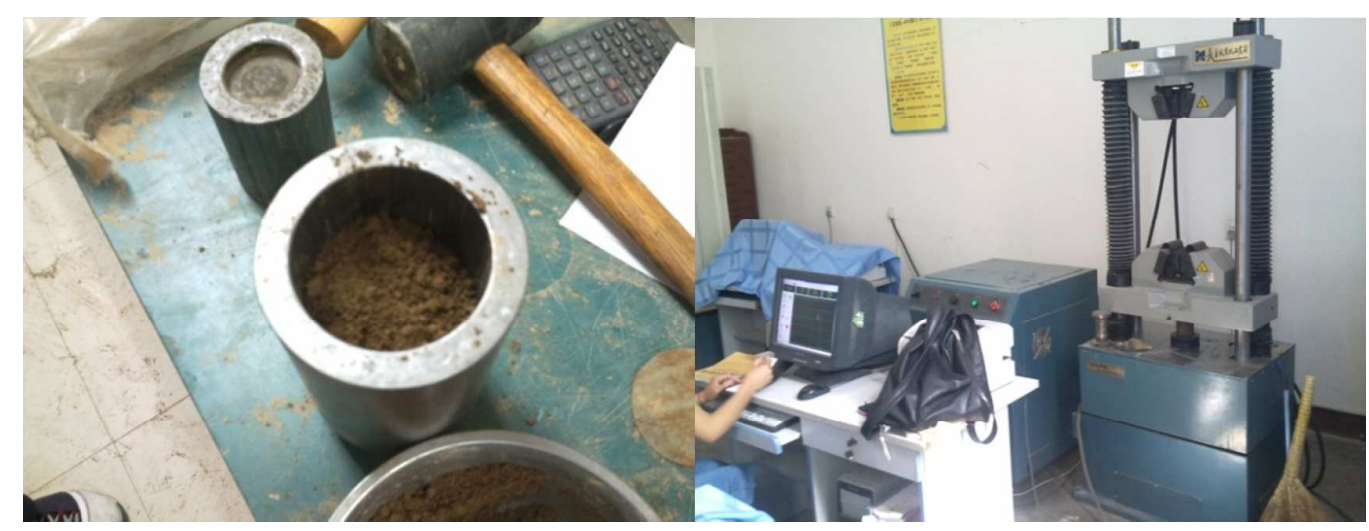




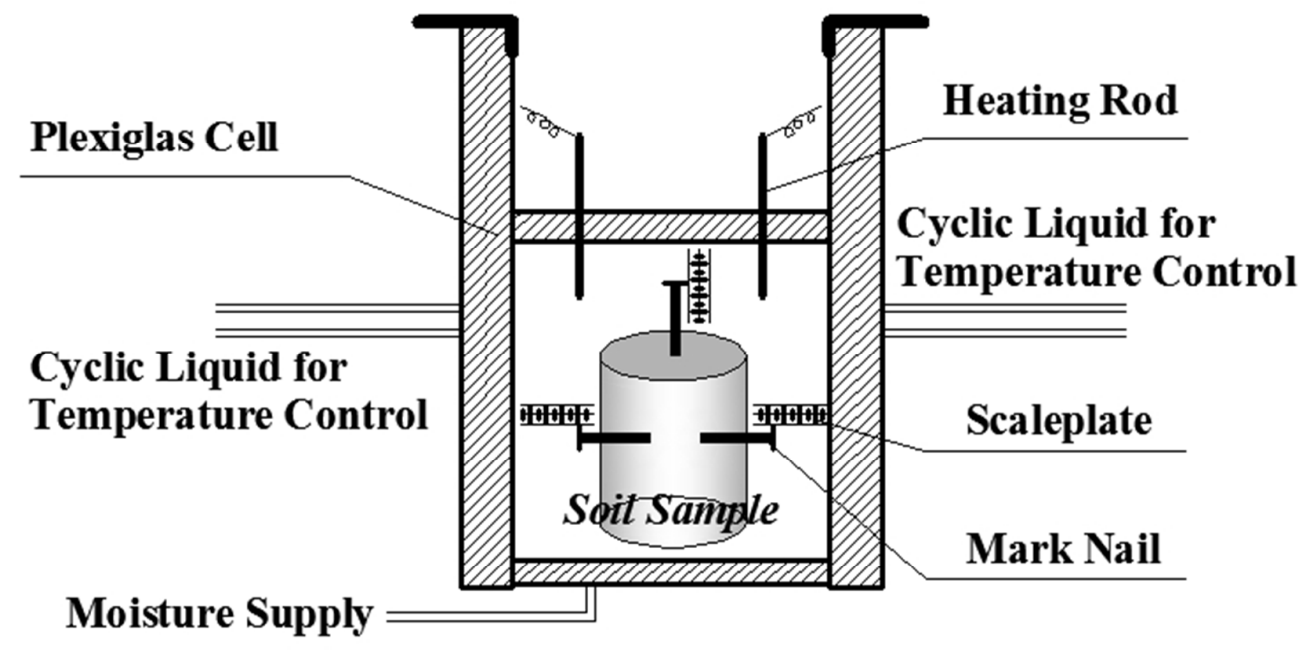




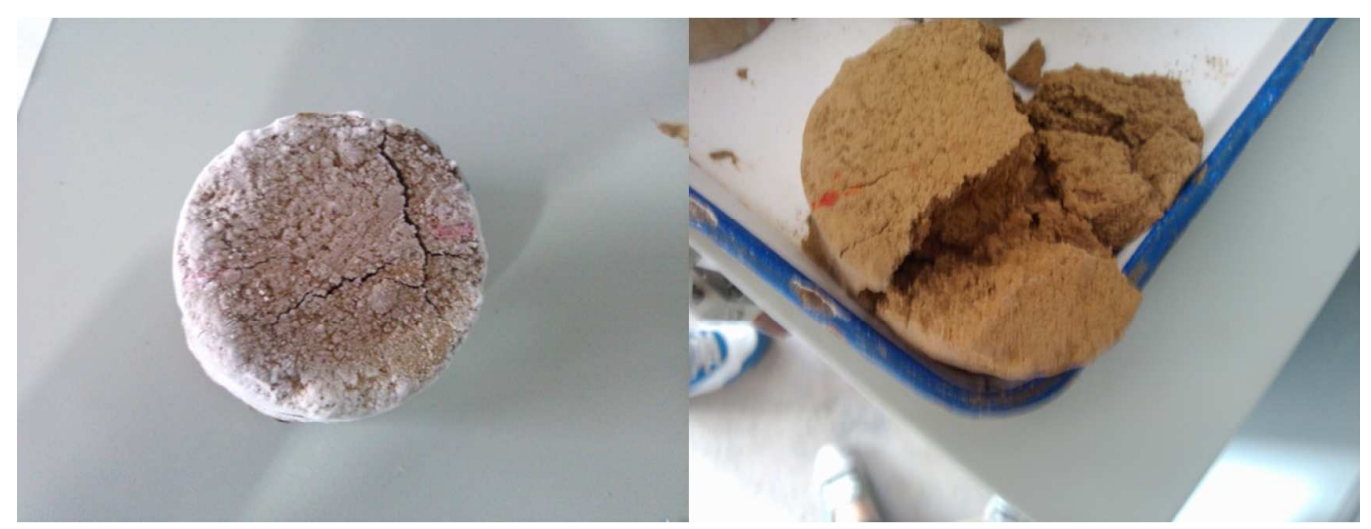

(a) loess after $168 \mathrm{~h}$

(b) loess after192h

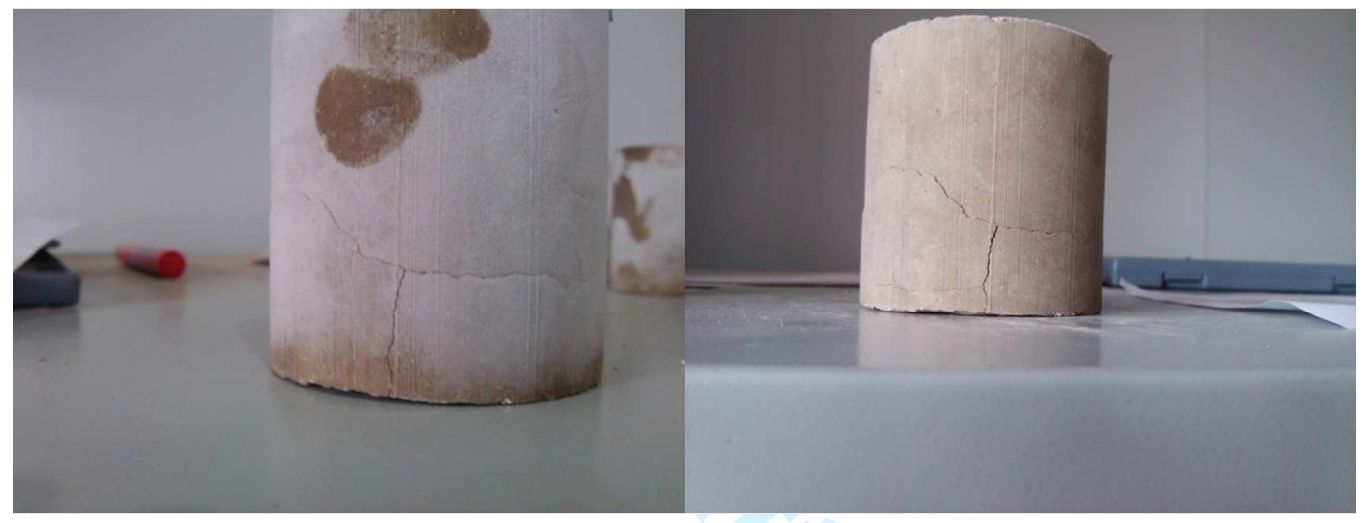

(c) B69 after 180h

(d) B69 after 192h

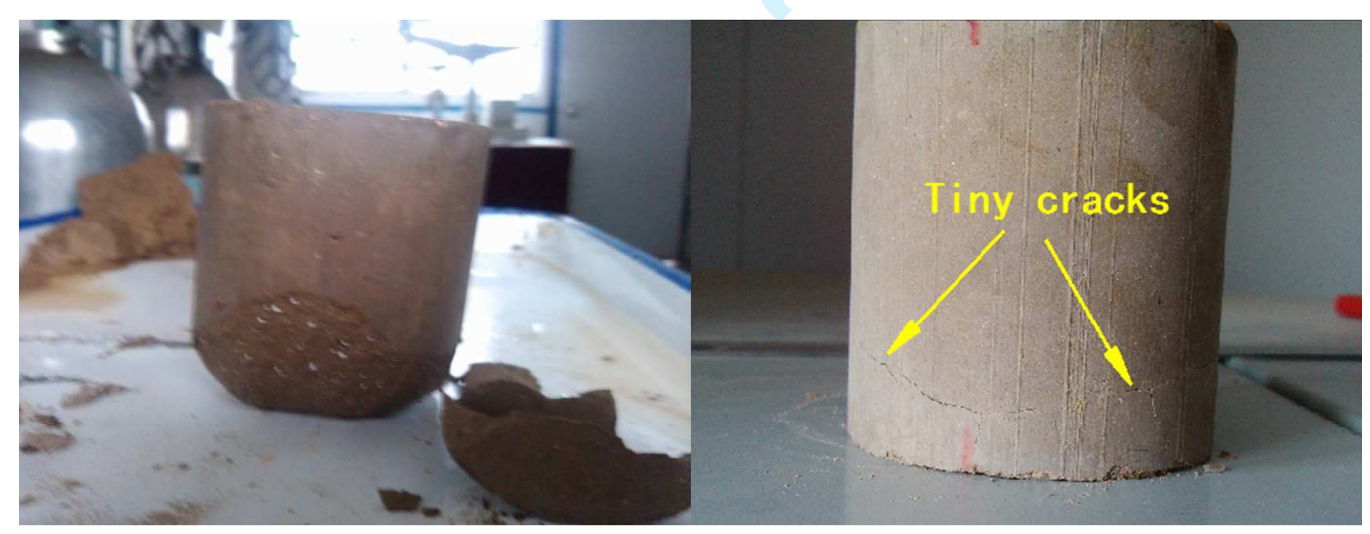

(e) B69 after 216h

(f) B66 after $192 \mathrm{~h}$ 


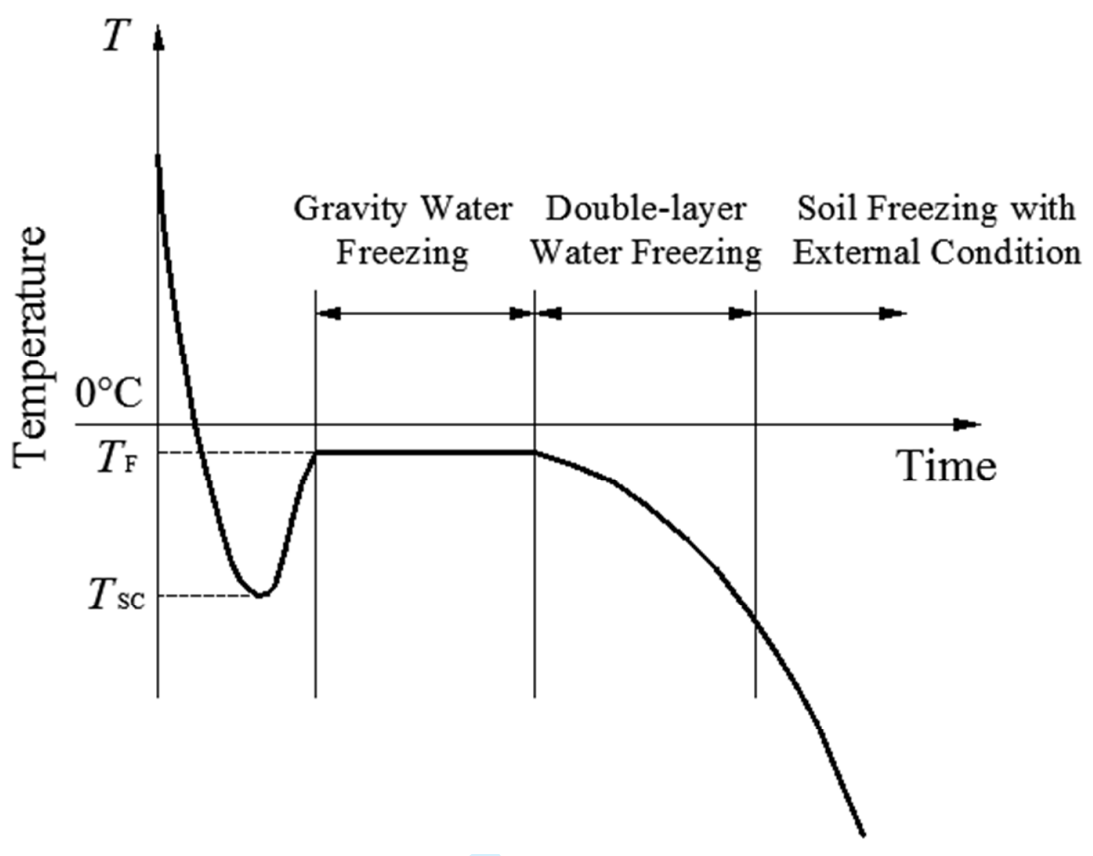




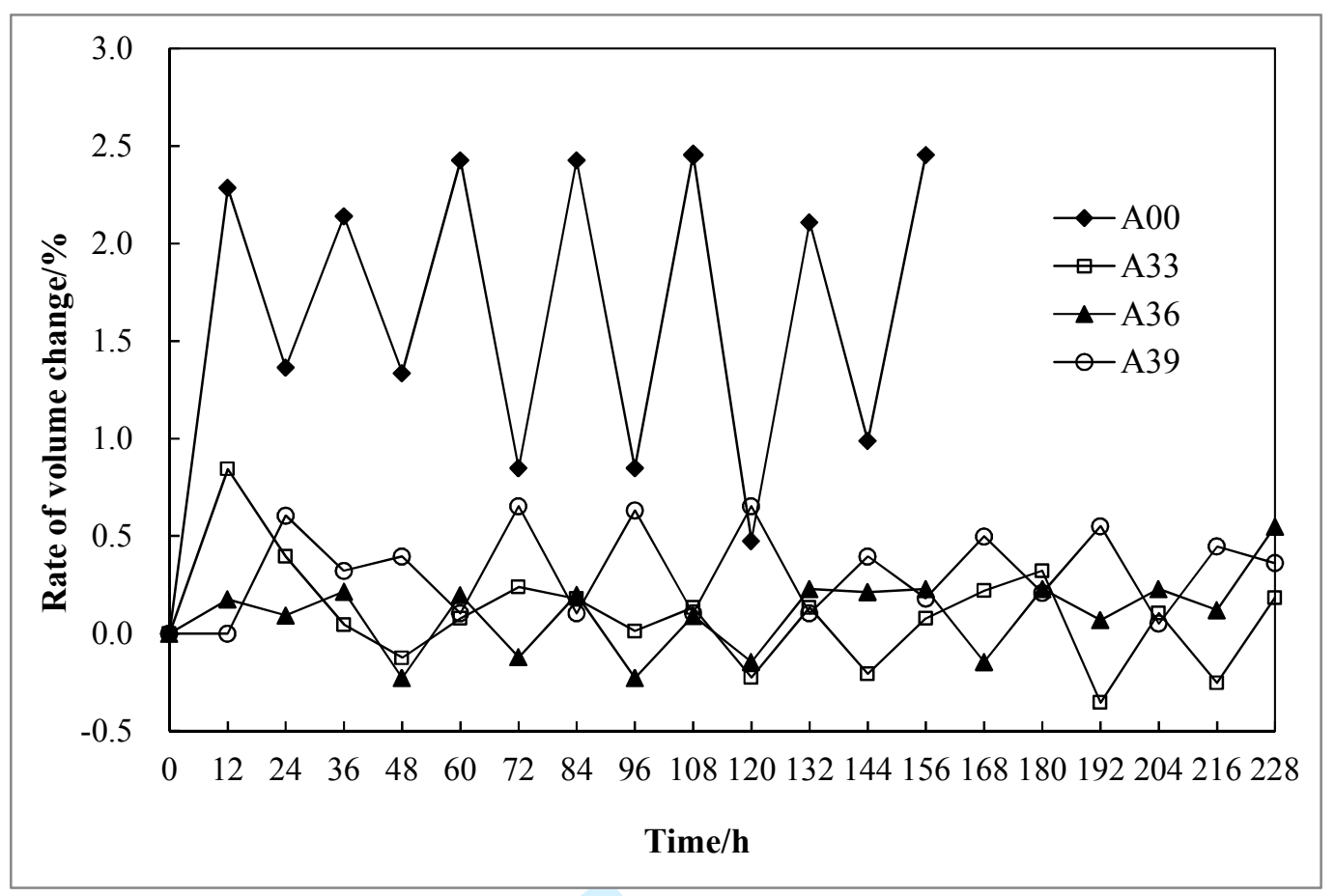




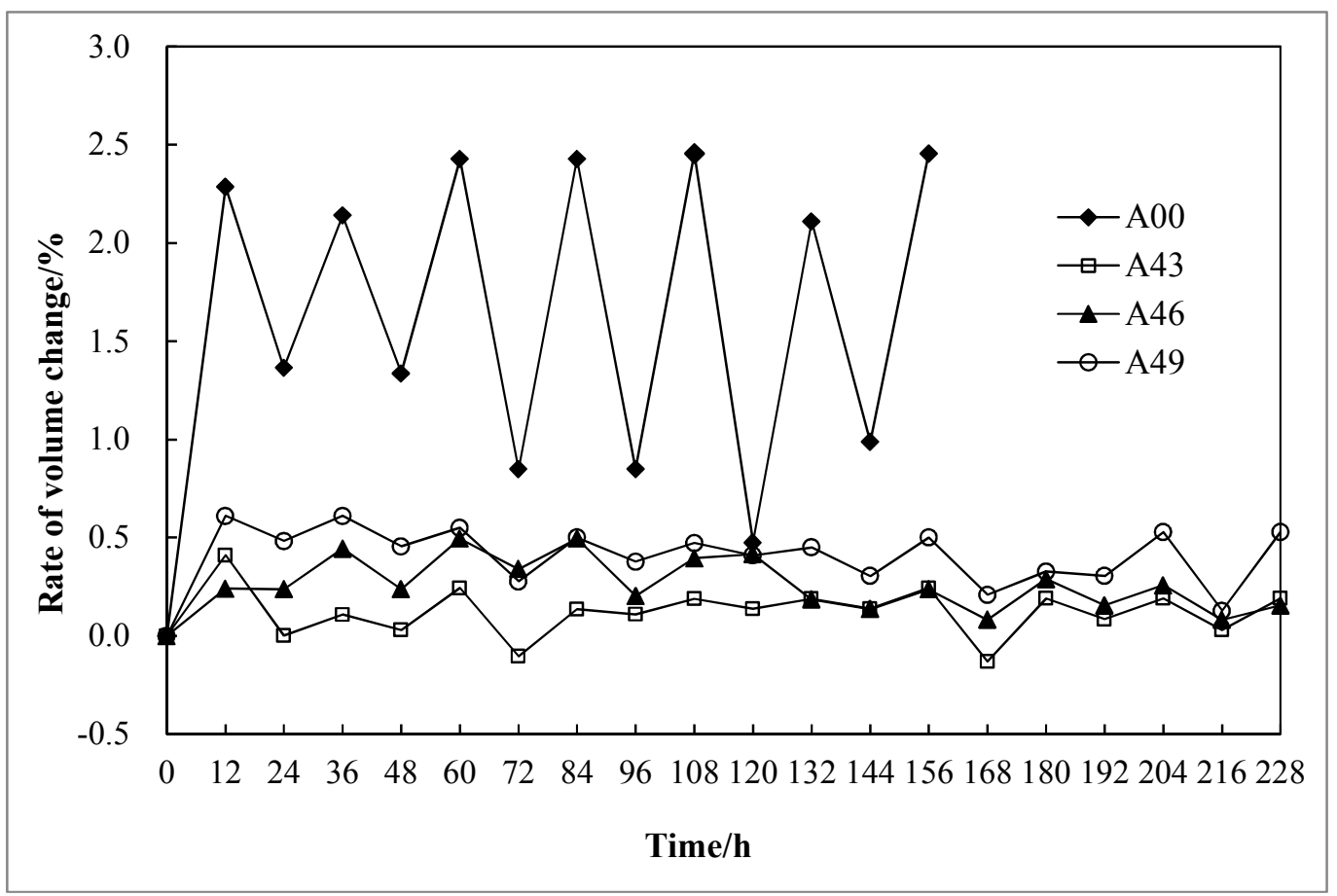




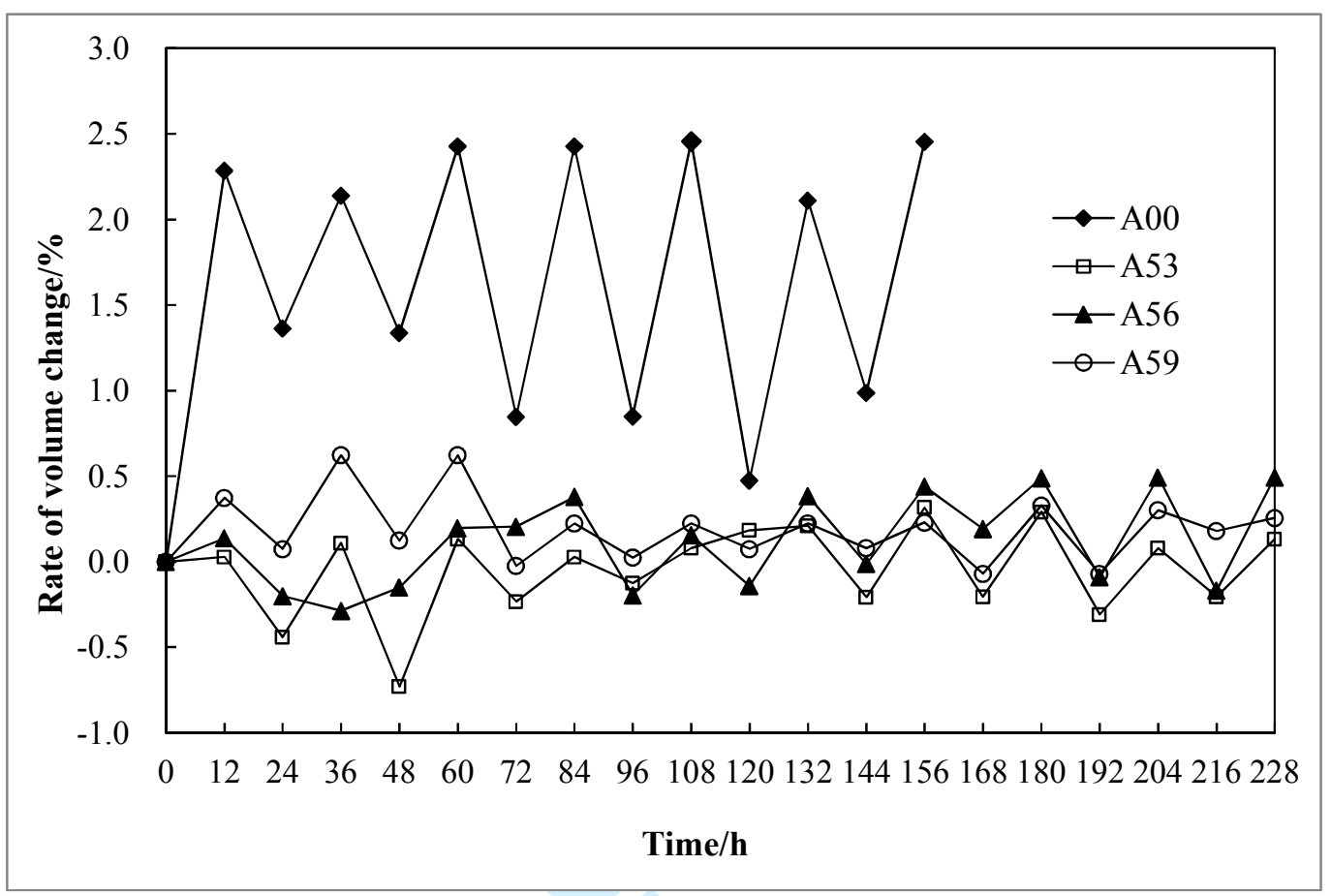




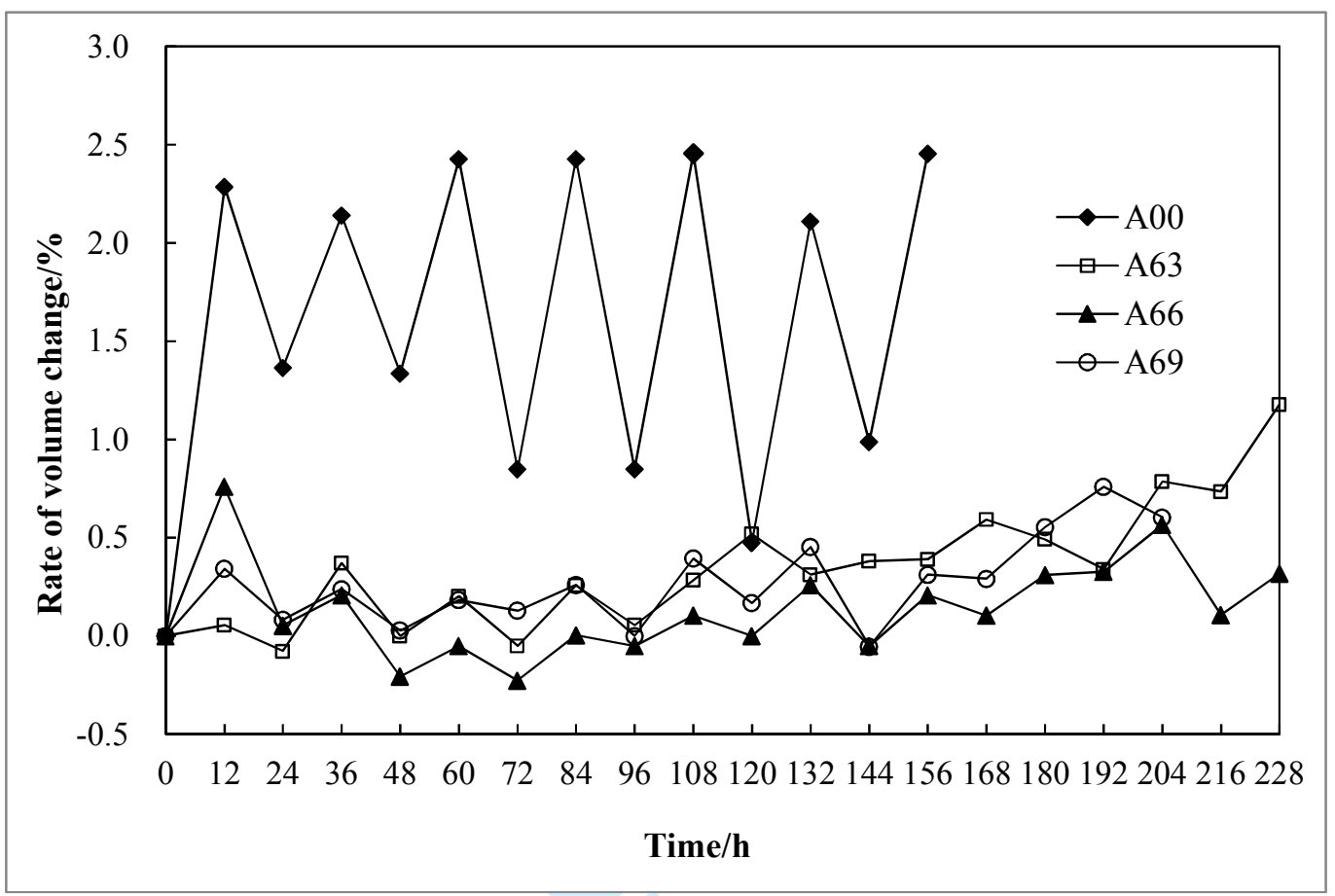




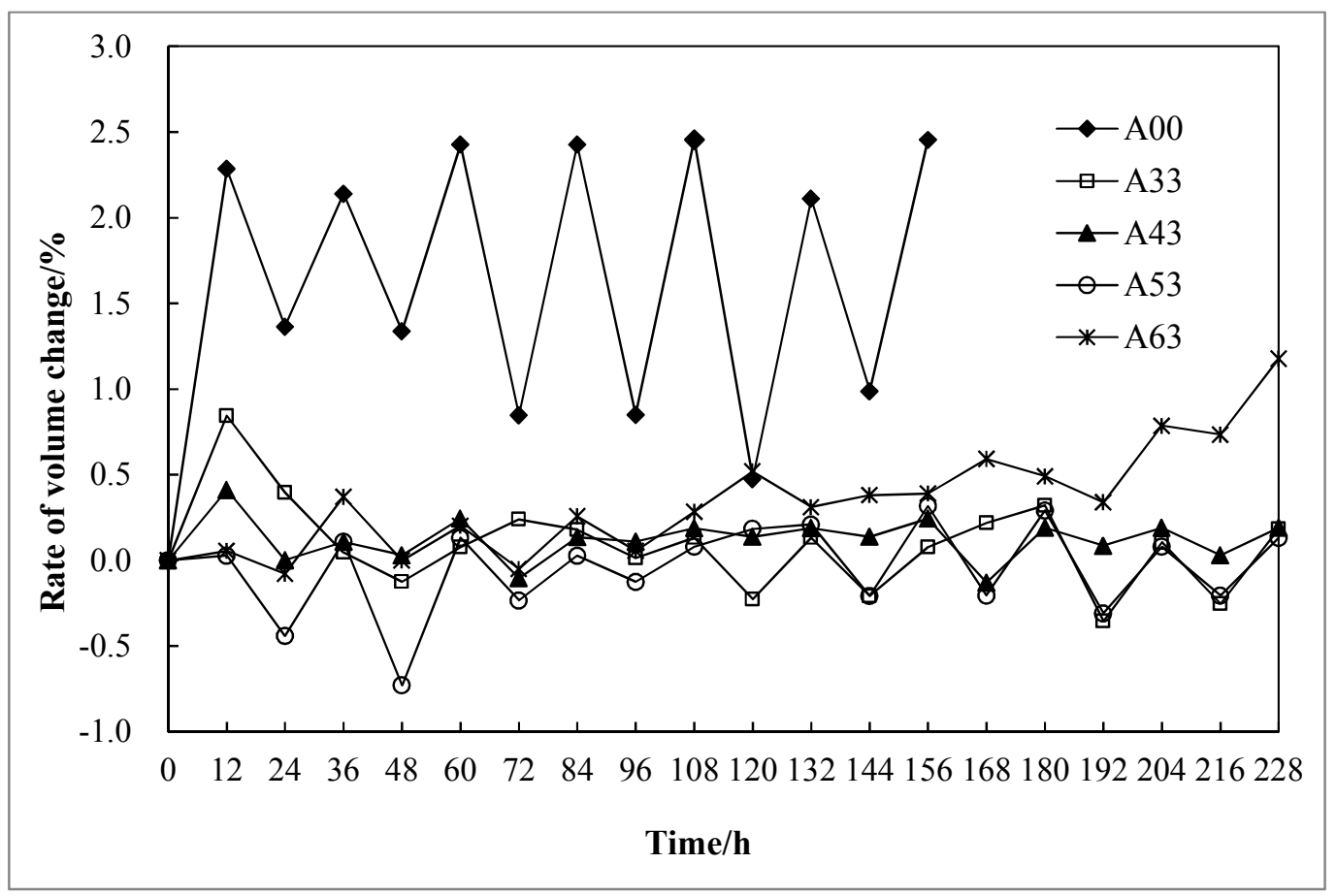




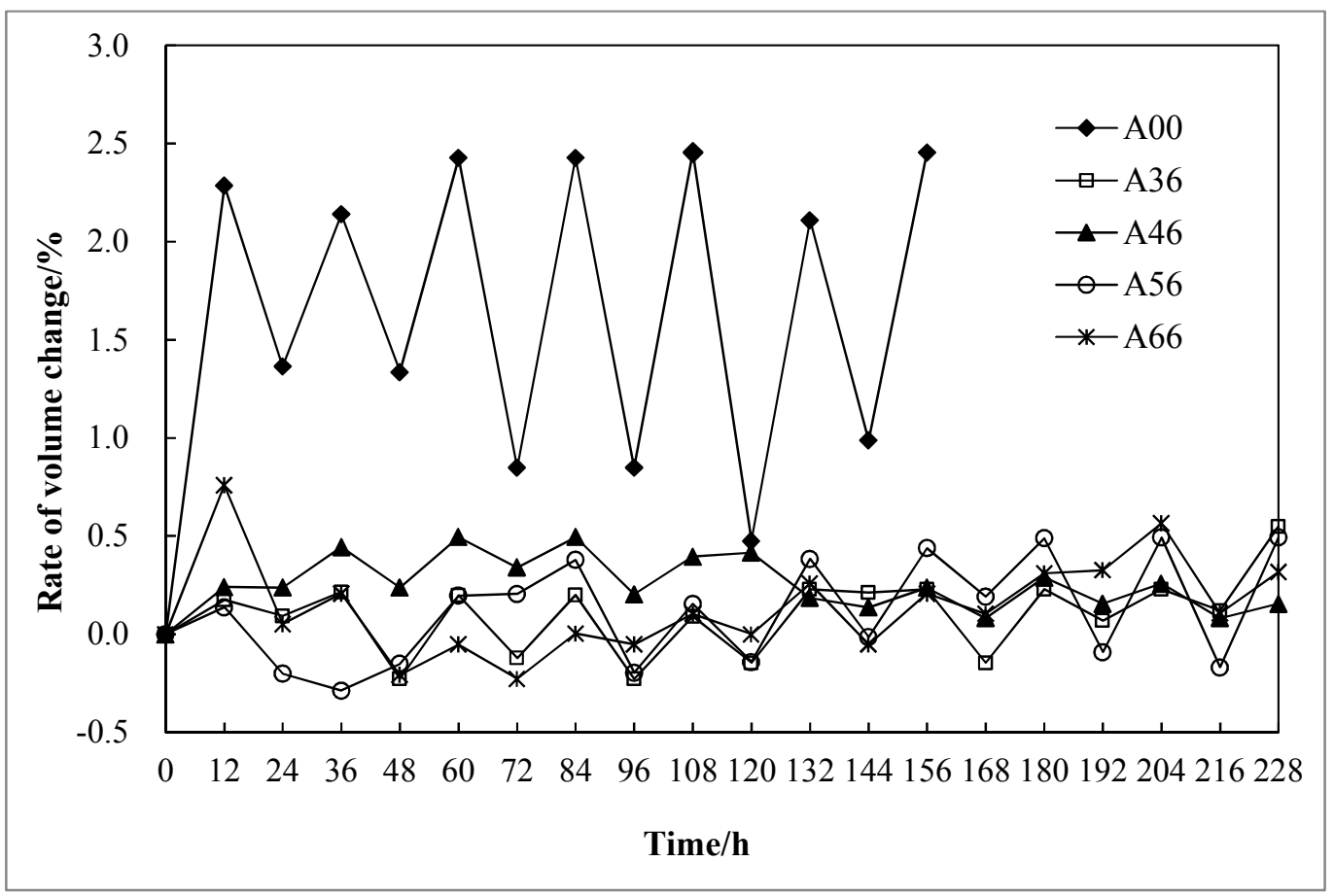




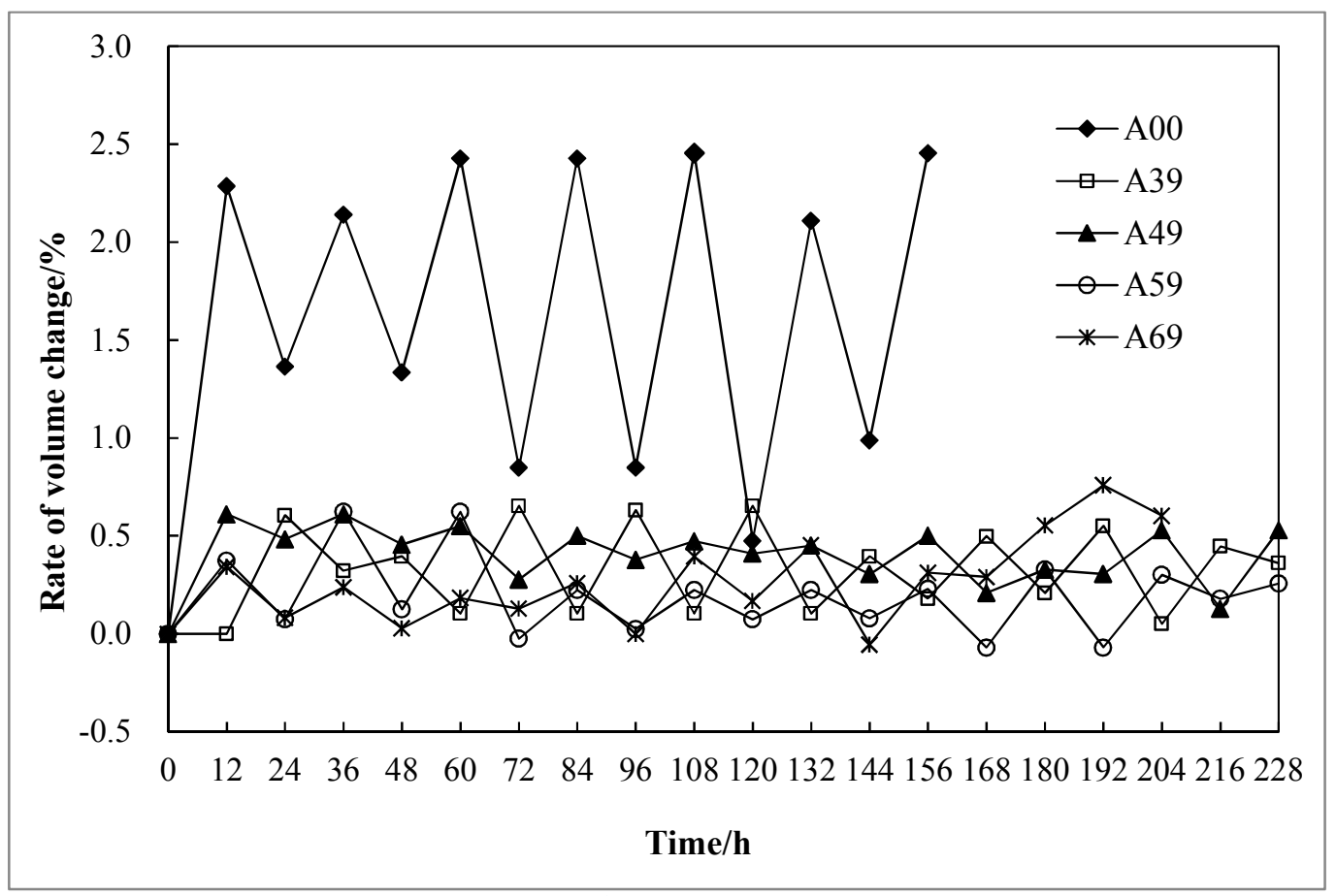




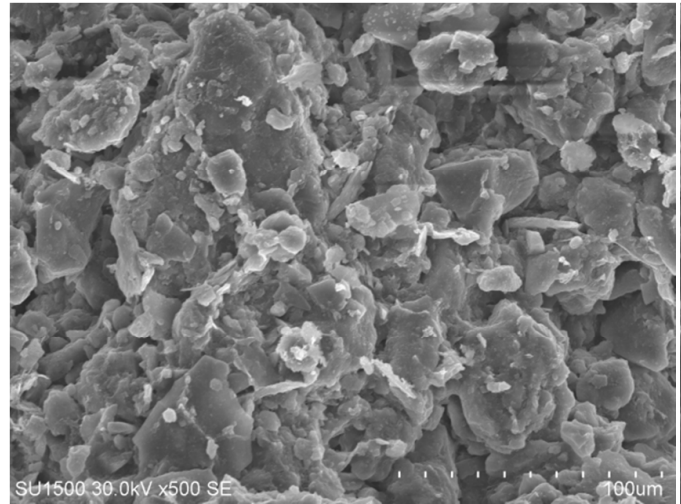

(a) Loess before cycles

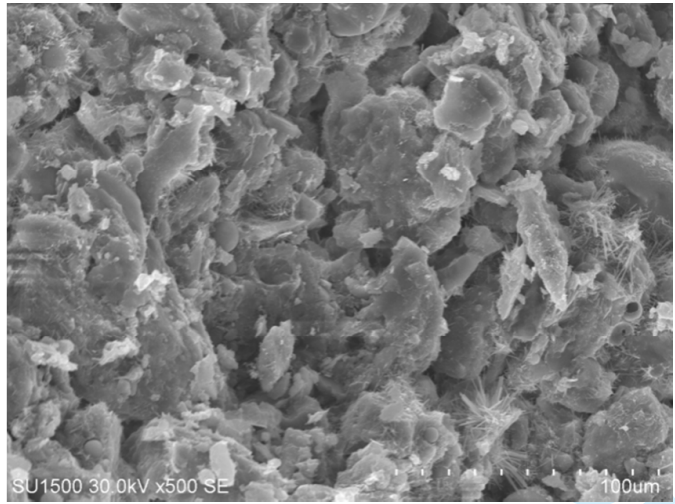

(c) 3\% cement and 3\% lime before freeze-thaw cycles

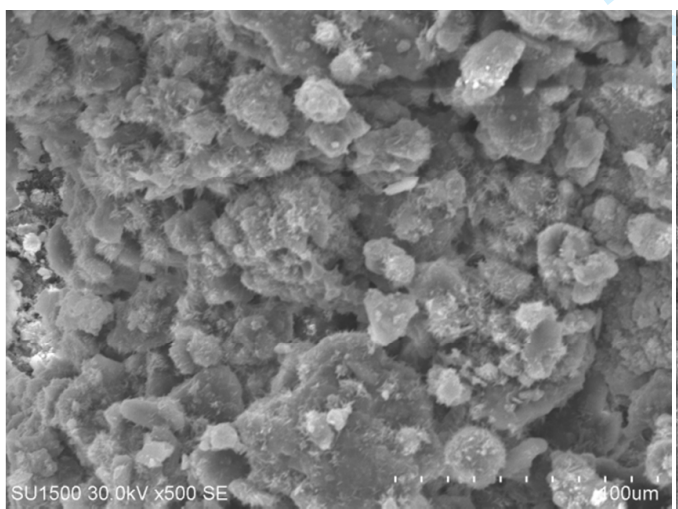

(e) $4 \%$ cement and $6 \%$ lime before freeze-thaw cycles

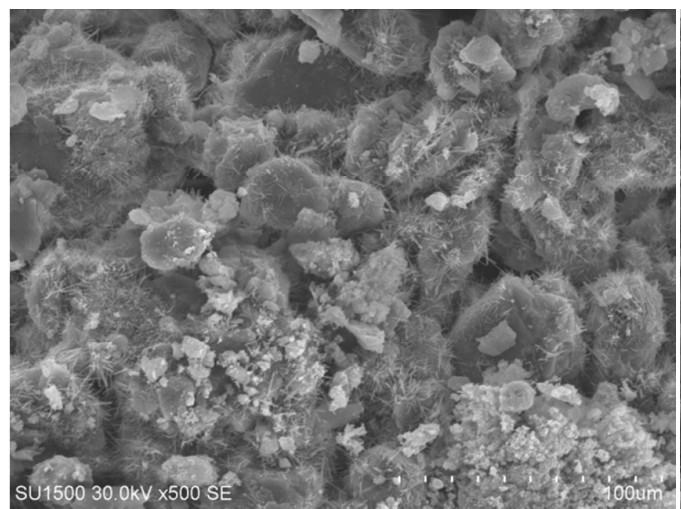

(g) $5 \%$ cement and $6 \%$ lime before freeze-thaw cycles

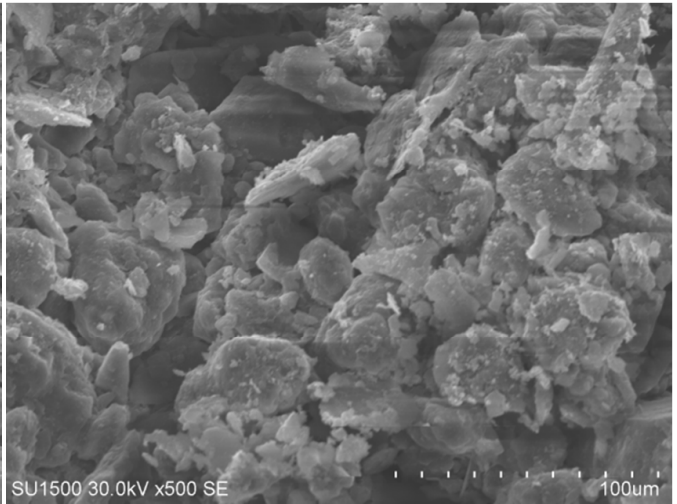

(b) Loess after cycles

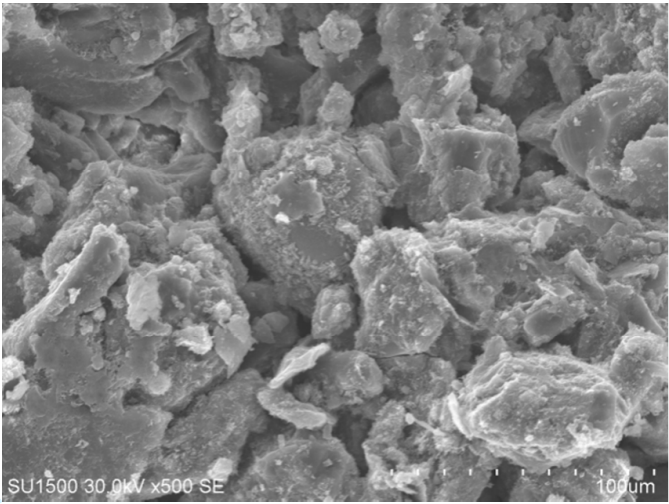

(d) $3 \%$ cement and 3\% lime after freeze-thaw cycles

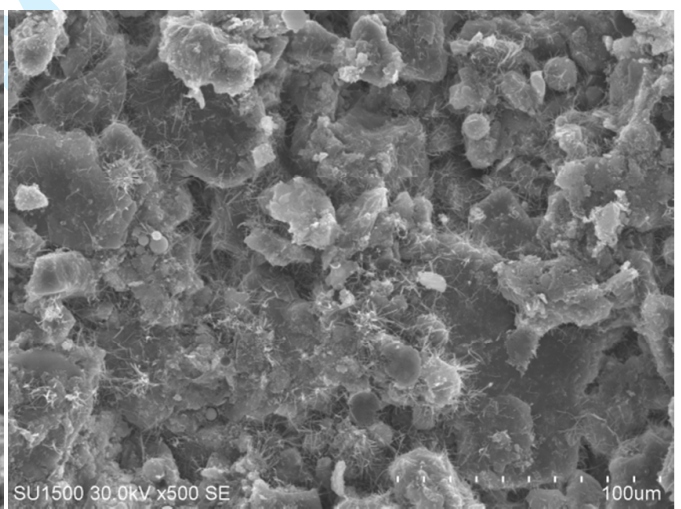

(f) $4 \%$ cement and $6 \%$ lime after freeze-thaw cycles

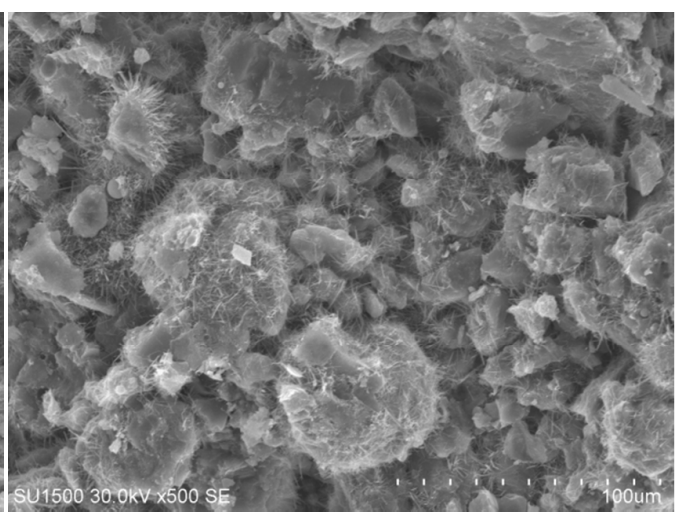

(h) $5 \%$ cement and $6 \%$ lime after freeze-thaw cycles 


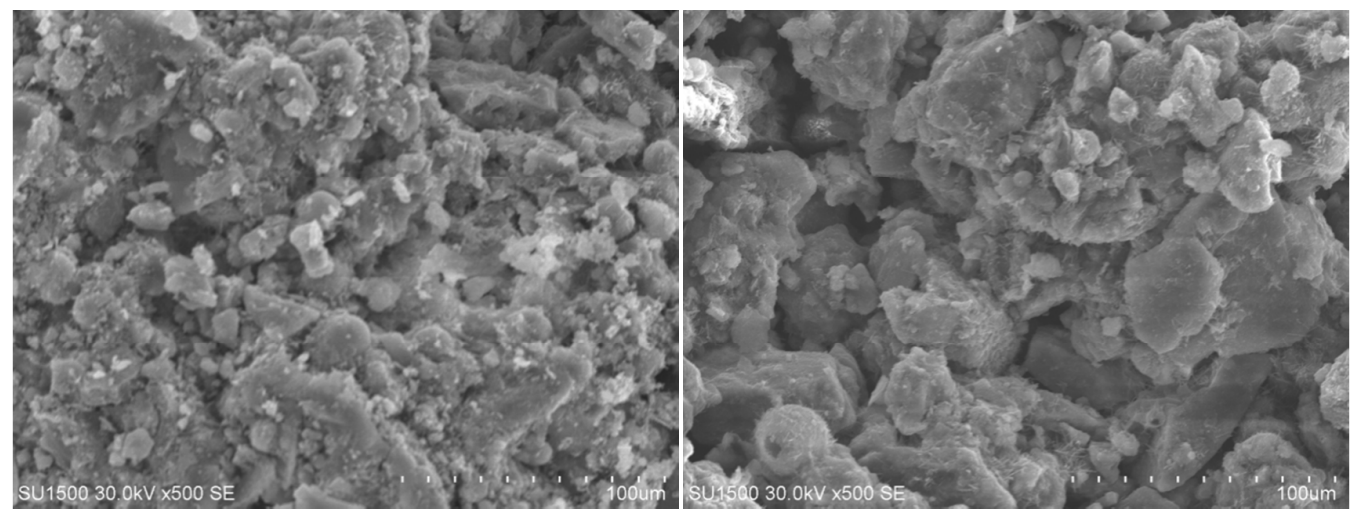

(i) $6 \%$ cement and $9 \%$ lime before freeze-thaw cycles

(j) $6 \%$ cement and $9 \%$ lime after freeze-thaw cycles 

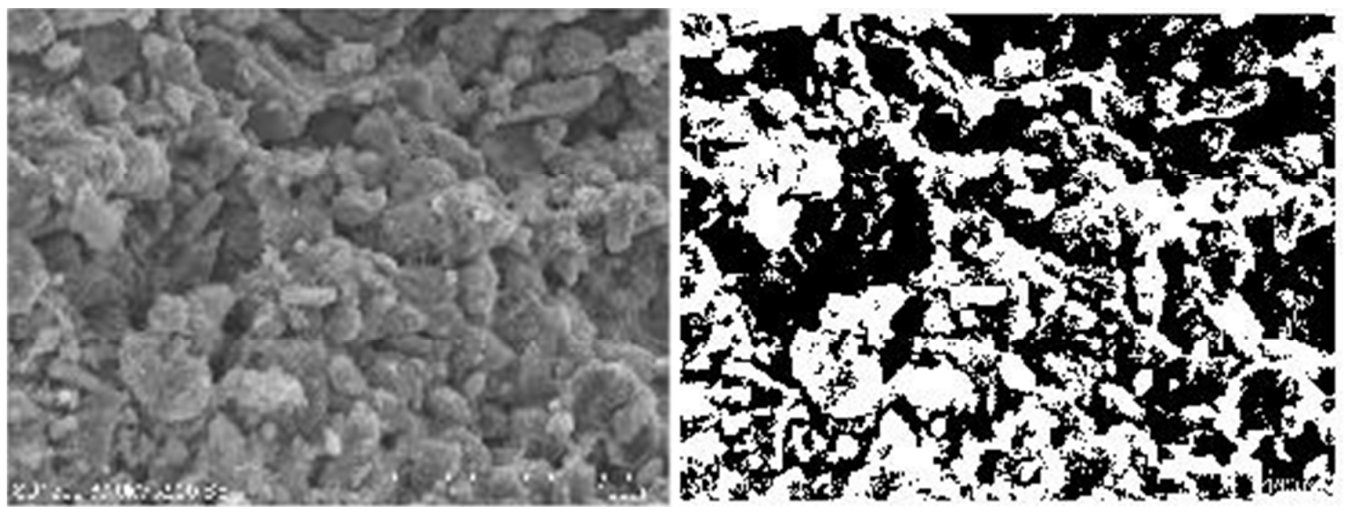


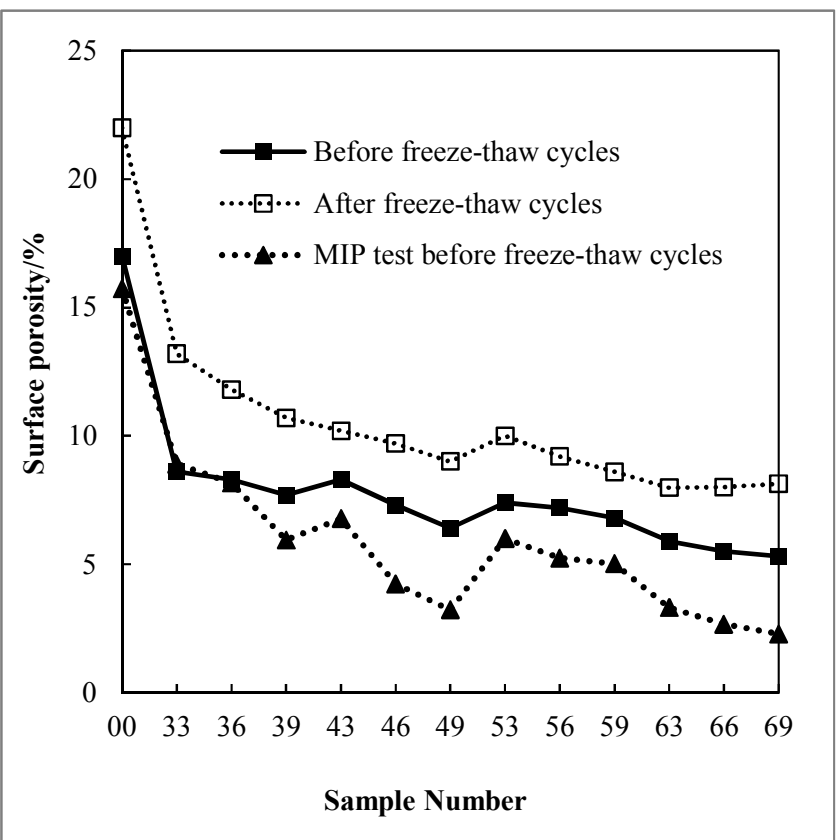

1

https://mc06.manuscriptcentral.com/cjce-pubs 


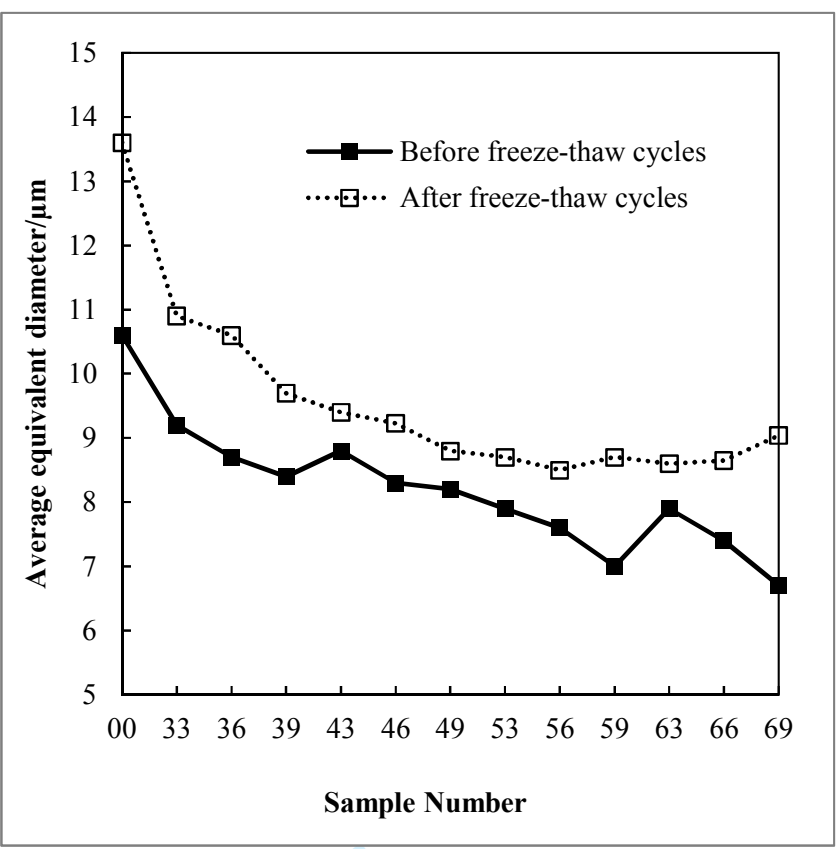

1

https://mc06.manuscriptcentral.com/cjce-pubs 